NISTIR 7292

\title{
Evaluation of an Inexpensive Method to Stabilize the Temperature of Machine tool Components
}

\author{
Mahn-Hee Hahn \\ M. Alkan Donmez \\ Johannes A. Soons
}


NISTIR 7292

\title{
Evaluation of an Inexpensive Method to Stabilize the Temperature of Machine Tool Components
}

\author{
Mahn-Hee Hahn \\ M. Alkan Donmez \\ Johannes A. Soons \\ Manufacturing Metrology Division \\ Manufacturing Engineering Laboratory \\ National Institute of Standards and Technology \\ Gaithersburg, MD 20899-8220
}

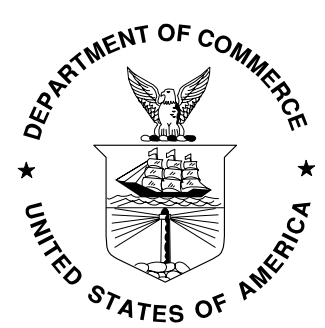

U.S. DEPARTMENT OF COMMERCE

Carlos M. Gutierrez, Secretary NATIONAL INSTITUTE OF STANDARDS AND TECHNOLOGY William Jeffrey, Director 


\title{
Evaluation of an Inexpensive Method to Stabilize the Temperature of Machine tool Components
}

\begin{abstract}
One of the best approaches for maintaining a uniform temperature across a machine tool structure and thus minimizing thermal deformations is removing the heat at the heat sources. This study evaluates the effectiveness of using inexpensive Personal Air Conditioner (PAC) tubing to remove heat from heat sources. The PAC tubing is a soft silicone extrusion with small, perforated slits through which cooling air is transferred. The PAC tubing increases heat dissipation from the heat sources through local forced convection and Coanda-effect cooling. The results of a series of tests conducted on a simulated motor showed that the motor shell temperature was reduced 28-fold compared to natural convection cooling. This leads to a conclusion that PAC tubing may be a viable alternative to cooling machine tool components to minimize thermal deformations.
\end{abstract}

Key words: PAC tubing, Coanda effect, convection heat transfer, temperature, simulated motor, machine tool components.

\section{Introduction}

Precision machining operations can be adversely affected if the machine tool structure or the part being machined is subject to temperature variations that result in unwanted thermal expansion. Machining accuracy can be improved by reducing temperature variations in the machine tool components. Ideally, the temperature of the whole machine tool and the part being machined should be at a constant and uniform temperature of $20^{\circ} \mathrm{C}$. In a traditional machine shop environment, such a goal cannot be achieved easily. However, minimizing temperature variations among the various machine tool components is an achievable objective for many machine designers.

Usually, heat generated at the interface between the cutting tool and the part being machined is removed by the coolant used in the cutting process. Heat removal from the other major heat sources such as drive motors and spindles is usually obtained by convection. Other means of cooling machine tool structures, such as liquid shower, liquid cooling coil systems, thermoelectric cooling, or vortex-type cooling, are effective but are considered difficult to implement and expensive solutions for existing machines. Liquid cooling is the most effective cooling method and has been proven to work well [1]. Liquid cooling systems are applied successfully to stabilize the temperature of spindles and lead screws (the main heat sources of a machines tool).

Alternatively, a constant temperature air shower supplied by an air conditioning unit can be used to reduce the temperature variations within the machine tool structures. However, due to both the poor heat transfer between the flowing air and the machine tool components, and the low heat capacity of the air, one has to provide large volumes of air at high speeds to make this method effective.

Cooling devices based on the Coanda effect are described in the literature as the most effective cooling method for some applications [2]. The Coanda effect is the tendency for a fluid emerging from a nozzle or orifice to follow a nearby surface if the curvature of the surface is not too large and the angle that the surface makes with the stream is not too sharp. The primary stream, "clinging" to the surface, acts as a fluid-powered fan and drags along a secondary stream of fluid that can be much larger than the primary 
stream. One experiment showed that the Coanda effect entrained up to 20 times the amount of air in the original jet [2]. The increased fluid flow can result in a substantial increase in the cooling of the surface.

There are commercially available cooling devices that utilize the Coanda effect. One such device, Personal Air Conditioner (PAC) tubing, consists of a soft extruded silicone tube with small slits as shown in Fig. 1. It is marketed for cooling a person working in a hot environment. When the tubing is pressurized by air, air escapes through the small slits and clings to the surface of the small flange. The escaping primary airflow will induce secondary airflow, which increases the cooling of the surface to which the PAC tubing is attached.

This paper presents the results of a feasibility study to examine the effectiveness of the PAC tubing system to cool machine tool components. The study was conducted by installing the PAC tubing on a simulated drive motor and measuring the effective convection heat transfer from this simulated heat source.

\section{Experimental Setup and Procedure}

A simulated motor, consisting of a hollow aluminum cylinder of $6.3 \mathrm{~mm}$ thick walls with an adhesivebacked foil heater attached to the inside surface, was fabricated as shown in Fig. 2. The cylinder was filled with Styrofoam insulation to ensure unidirectional heat flow. PAC tubing was wrapped around the outer cylindrical surface to examine the convection generated by PAC tubing. The surface temperatures of the cylinder were measured using twelve Type-T thermocouples mounted on the outer cylindrical surface and one each on the end covers of the cylinder. In addition, one thermocouple was placed in the inlet air stream of the tubing, and two thermocouples were used to measure the ambient temperature near the cylinder.

There are two types of PAC tubing available: SF ( $4.8 \mathrm{~mm}$ hole diameter) and HF ( $7.9 \mathrm{~mm}$ hole diameter) as shown in Fig. 3. Tests were carried out with both types of tubing. A vortex-cooling device specifically designed for PAC tubing can be used to cool the supply air below room temperature. A vortex device is a device to generate hot and cold air from compressed air. To use a vortex device, simply connect compressed air to the inlet port of a vortex device and cold air comes out at the outlet port. The vortex device is inserted in line with an airline. Tests were conducted with and without a vortex-cooling device. To examine the influence of the tube spacing on the cooling performance, the tubing was spirally wrapped around the cylinder at four different pitch spacings $(38 \mathrm{~mm}, 50 \mathrm{~mm}, 75 \mathrm{~mm}$, or $100 \mathrm{~mm}$ ) as shown in Fig. 2.

The original SF and HF tubing are designed to cool a person, and the perforations are punched just below the two upper lips. To improve PAC tube efficiency for surface cooling, new tubing was fabricated by punching the slits closer to the lower lip. The new tube designs of NSF (modified from SF) and NHF (modified from HF) tubing are tested and shown in Fig. 3.

A constant voltage was applied to the electrical heater of the simulated motor at various voltages (about $10 \mathrm{~V}, 20 \mathrm{~V}, 30 \mathrm{~V}$, and $38 \mathrm{~V}$ ), and the power input was calculated by multiplying the voltage and current to the heater (about $6 \mathrm{~W}, 23 \mathrm{~W}, 53 \mathrm{~W}$, and $84 \mathrm{~W}$ ). Steady-state conditions were reached in about one hour after changing the heater voltage. Temperatures were measured at 5-min intervals for $1 \mathrm{~h}$. The steady-state temperature provides a measure of the effective heat transfer. 
Compressed air was circulated through the PAC tubing to generate the Coanda effect. Throughout the experiments, it was observed that the air pressure varied between $530 \mathrm{kPa}$ and $689 \mathrm{kPa}$.

To investigate the radiation component of heat transfer, tests were run without PAC tubing, with the outer aluminum surface of the simulated motor left bare, and with the surface painted black. A Gier and Dunkle Radiometer was used to measure the emissivity of bare and painted aluminum surfaces with the results being 0.039 and 0.788 , respectively.

The simulated motor was also tested under blower cooling without PAC tubing. A $300 \mathrm{~W}$ blower was placed $600 \mathrm{~mm}$ in front of the simulated motor, and its speed varied at low, medium, and high. The air velocity in front of the simulated motor was measured with an air velocity meter and found to be $1.7 \mathrm{~m} / \mathrm{s}$, $2.6 \mathrm{~m} / \mathrm{s}$, and $3.4 \mathrm{~m} / \mathrm{s}$, respectively, for the three speeds.

\section{Analysis Procedures}

The total heat loss from the simulated motor consisting of both convective and radiative heat transfer can be expressed as [3]:

$$
P=P_{\mathrm{c}}+P_{\mathrm{r}} \approx\left(h_{\mathrm{c}}+h_{\mathrm{r}}\right) \mathrm{A} \Delta T
$$

where $P$ : Electrical power input $(\mathrm{W})$

$P_{c}$ : Heat loss by convection (W)

$P_{r}$ : Heat loss by radiation (W)

$h_{c}$ : Convection coefficient $\left(\mathrm{Wm}^{-2} \mathrm{~K}^{-1}\right)$

$h_{r}$ : Radiation coefficient $\left(\mathrm{Wm}^{-2} \mathrm{~K}^{-1}\right)$

$A$ : Surface area of cylinder including both end surfaces $\left(\mathrm{m}^{2}\right)$

$\Delta T=T_{s}-T_{a}$

$T_{s}$ : Average surface temperature of cylinder $(\mathrm{K})$

$T_{a}:$ Ambient temperature $(\mathrm{K})$

The radiative heat transfer is given by

$$
P_{r}=\varepsilon \sigma \mathrm{A}\left(T_{s}^{4}-T_{a}^{4}\right) \approx 4 \varepsilon \sigma T_{m}^{3} \mathrm{~A} \Delta T=h_{r} \mathrm{~A} \Delta T
$$

where $\varepsilon$ : Total hemispherical emissivity of the radiating surface

$\sigma:$ Stefan-Boltzmann constant $\left(5.669 \times 10^{-8} \mathrm{Wm}^{-2} \mathrm{~K}^{-4}\right)$

$T_{m}=\left(T_{s}+T_{a}\right) / 2$

The use of a radiation coefficient is justified when the temperature difference, $\Delta T$, between the surface and the ambient is small compared to the mean absolute temperature, $T_{m}$, which is the case for the present study. The radiative component of heat transfer can be computed from Eq. (2) and is subtracted from the measured input power to obtain the convective component of heat transfer. The experimental data are presented as plots of $\Delta T$ versus convective power loss, $P_{c}$. The slopes of these plots are indicators of convective heat transfer coefficients. 


\section{Test Results}

Fig. 4 shows the test results when the simulated motor was heated under natural convection conditions to establish a base line for the study. In this plot, the ordinate is the observed difference between the steady-state surface temperature of the cylinder and the average ambient temperature, $\Delta T$. The abscissa is either the radiated power, $P_{r}$, computed from Eq. (2) using the measured emissivities, or the power lost by natural convection, $P_{c}$. The latter is computed by subtracting the radiated power from the total power, $P$, input by the heating element. Thus, the slopes of the curves are inversely correlated to the radiation and convection coefficients, $\mathrm{h}_{\mathrm{r}}$ and $\mathrm{h}_{\mathrm{c}}$. These data show that when the simulated motor is painted black, the radiative heat loss and the heat lost by natural convection are nearly equal. The radiative heat loss from the bare aluminum cylinder is very small compared to the loss by natural convection. Since all of the tests with PAC tubing were done with the cylinder unpainted, radiative heat loss was not considered further in the remainder of this report.

The graph of $\Delta T$ versus convective heat loss for SF tubing, used with a vortex device, is shown in Fig. 5. Measurements were performed with the tubing installed with $38 \mathrm{~mm}, 50 \mathrm{~mm}, 75 \mathrm{~mm}$, and $100 \mathrm{~mm}$ pitch spacings, as shown in Fig. 2. Because of the cooling provided by the vortex tube, the surface of the simulated motor is colder than the ambient temperature for the lower power inputs, creating a negative $\Delta T$. With $38 \mathrm{~mm}$ pitch spacing at $84 \mathrm{~W}, \Delta T$ is $4.7 \mathrm{~K}$. However, when only natural convection is present as shown in Fig. $4, \Delta T$ is $80.7 \mathrm{~K}$. The improvement over natural convection is by a factor of 17.

The graph of $\Delta T$ versus convective heat loss for HF tubing used in conjunction with the vortex device is shown in Fig. 6 for the same pitch spacing. For this test, the smallest $\Delta T$ occurred for the $100 \mathrm{~mm}$ pitch spacing, probably because of the lower flow resistance associated with the shorter length at this pitch.

The lowest $\Delta T$ for these tests is $7.3 \mathrm{~K}$, as compared with $4.7 \mathrm{~K}$ as shown in Fig. 5, indicating that the HF tubing with the vortex tube is less effective than the SF tubing with the vortex device.

Tests without a vortex device are shown in Fig. 7 and Fig. 8 for SF and HF tubing, respectively. In Fig. 7 , the $\Delta T$ is $3.3 \mathrm{~K}$ at $84 \mathrm{~W}$ for $100 \mathrm{~mm}$ pitch spacing. Fig. 8 shows that in HF tubing without the vortex device, the smallest $\Delta T$ is $6.6 \mathrm{~K}$ at $85 \mathrm{~W}$ for the $75 \mathrm{~mm}$ and $100 \mathrm{~mm}$ pitch spacings.

The test results of NSF and NHF tubing with vortex device are shown in Fig. 9 and Fig. 10, respectively. Fig. 9 shows that the effect of tubing spacing is small, but the $\Delta T$ for the $50 \mathrm{~mm}$ pitch spacing is somewhat better than that for the $38 \mathrm{~mm}, 75 \mathrm{~mm}$, and $100 \mathrm{~mm}$ pitch spacings. In the $84 \mathrm{~W}$ ranges, the $\Delta T$ is $4.9 \mathrm{~K}$ for the $50 \mathrm{~mm}$ pitch spacing. Fig. 10 shows that the effect of pitch spacing is again small, but the $\Delta T$ for $75 \mathrm{~mm}$ pitch spacing is better than that for the $38 \mathrm{~mm}, 50 \mathrm{~mm}$, and $100 \mathrm{~mm}$ pitch spacings. At $84 \mathrm{~W}, \Delta T$ is $6.6 \mathrm{~K}$ for the $75 \mathrm{~mm}$ pitch spacing.

The test results of NSF and NHF without cooling from the vortex device are shown in Fig. 11 and Fig. 12 , respectively. Fig. 11 shows that the minimum $\Delta T$ is $2.8 \mathrm{~K}$ at $84 \mathrm{~W}$ for the $75 \mathrm{~mm}$ and $100 \mathrm{~mm}$ pitch spacings. This is the lowest $\Delta T$ observed in this study and represents an improvement by a factor of 28 over the data obtained with only natural convection. As shown in Fig. 12, the minimum $\Delta T$ is $4.7 \mathrm{~K}$ at $84 \mathrm{~W}$ for $100 \mathrm{~mm}$ pitch spacing.

The temperature differences under the condition of blower cooling of the simulated motor (without PAC tubing) are shown in Fig. 13 for three air speeds: $1.7 \mathrm{~m} / \mathrm{s}, 2.6 \mathrm{~m} / \mathrm{s}$, and $3.4 \mathrm{~m} / \mathrm{s}$. As expected, more cooling occurs with higher speeds, but not as much as occurs with PAC tubing. As shown in Fig. 13, $\Delta T$ at $84 \mathrm{~W}$ with high speed is $10 \mathrm{~K}$. 
The average $\Delta T$ for each type of PAC tubing is shown in Fig. 14, where the data have been averaged over the four pitch spacings. Also shown are the data obtained with the blower, averaged over the three blower speeds, and the natural convection data. At $84 \mathrm{~W}$, the average $\Delta T$ dropped from $80.7 \mathrm{~K}$ for natural convection to $12.4 \mathrm{~K}$ for the blower and to an average of $5.8 \mathrm{~K}$ for all of the PAC tubing tests.

The best PAC tubing test results were for NSF tubing without vortex device at either $75 \mathrm{~mm}$ or $100 \mathrm{~mm}$ pitch spacings yielding a $\Delta T$ of $2.8 \mathrm{~K}$ at $84 \mathrm{~W}$.

Most of the test results are presented in $\Delta T$, but convection coefficients provide for a more generic description of heat transfer improvement. Therefore, convection coefficients are calculated and summarized in Figs. 15 and 16. The plot of the convection coefficient, $h_{c}$, calculated from Eq. 4, using maximum $P_{c}$ around $84 \mathrm{~W}$, is shown in Fig. 15. The maximum $h_{c}$ occurs on NSF tubing without the vortex device at $75 \mathrm{~mm}$ spacing with $186 \mathrm{Wm}^{-2} \mathrm{~K}^{-1}$. The next best result occurs on NSF tubing without the vortex device at $100 \mathrm{~mm}$ spacing with

$179 \mathrm{Wm}^{-2} \mathrm{~K}^{-1}$. The third best result occurs on NSF tubing without vortex device at $50 \mathrm{~mm}$ spacing with $156 \mathrm{Wm}^{-2} \mathrm{~K}^{-1}$. The fourth best result occurs on SF tubing without the vortex device at $100 \mathrm{~mm}$ spacing with $155 \mathrm{Wm}^{-2} \mathrm{~K}^{-1}$. In general, the convection heat transfer increased as the airflow increases. As pitch spacing increases, the length of PAC tubing becomes shorter, and the airflow per hole increases. That means $100 \mathrm{~mm}$ and $75 \mathrm{~mm}$ pitch spacings are better than $50 \mathrm{~mm}$ and $38 \mathrm{~mm}$ pitch spacings. The convection coefficients averaged over the $38 \mathrm{~mm}, 50 \mathrm{~mm}, 75 \mathrm{~mm}$, and $100 \mathrm{~mm}$ pitch spacings are plotted in Fig. 16. From Fig. 16, the average improvement of convection coefficient of PAC tubing without the vortex device test is $180 \%$ compare with that of with the vortex device. The average improvement of PAC tubing test without the vortex device is $264 \%$ greater than that of the blower test. The average improvement of PAC tubing test without the vortex device is $1650 \%$ greater than tests without PAC tubing test, i.e., by natural convection.

Airflow rate with the vortex device for SF, HF, NSF, and NHF ranged from $57.5 \mathrm{~L} / \mathrm{min}$ to $70 \mathrm{~L} / \mathrm{min}$. Airflow rate without the vortex device for SF, HF, NSF, and NHF ranged from $204 \mathrm{~L} / \mathrm{min}$ to $255 \mathrm{~L} / \mathrm{min}$. The higher airflow explains the higher values of $h_{c}$.

\section{Discussion}

It was indicated earlier that the slopes of the $\Delta T$ versus $P_{c}$ plots represent the effective convective heat transfer coefficient according to Eq. (1). The non-zero intercepts observed in these plots are due to the effects of mixing the air temperature flowing out of the PAC tubing with the actual ambient temperature. If we define a representative ambient temperature $T_{a}$ ' as the (unknown) temperature of this air mixture, then the convection relationship can be re-written as

$$
\begin{array}{ll} 
& P_{\mathrm{c}}=\mathrm{A} h_{c}\left(T_{\mathrm{s}}-T_{\mathrm{a}}{ }^{\prime}\right) \\
& P_{\mathrm{c}}=A h_{c}\left(\left(T_{\mathrm{s}}-T_{\mathrm{a}}\right)-\left(T_{\mathrm{a}}{ }^{\prime}-T_{\mathrm{a}}\right)\right) \\
& P_{\mathrm{c}}=\mathrm{A} h_{c}\left(\Delta T-\Delta T_{0}\right) \\
\text { where } \quad & \Delta T_{0}=T_{\mathrm{a}}-T_{\mathrm{a}}
\end{array}
$$

Eq. (3) can be rewritten as:

$$
\Delta T=\frac{P_{c}}{h_{c} A}+\Delta T_{0}
$$


In Eq. (4), $\Delta T_{0}$ represents the temperature difference at $P_{c}=0$ (intercept of $\Delta T$ ) resulting from the mixture of air out of PAC tubing and the actual ambient air. When using the vortex device, the air temperature in the PAC tubing is cooled, reducing the temperature of the mixture with respect to the actual ambient, which results in the negative value of $\Delta T_{0}$.

To compare the results with previous published works, the natural convection from a horizontal cylinder of infinite length is expressed in Holman [4]:

$$
h_{c}=1.32(\Delta T / \mathrm{d})^{0.25}
$$

where $d$ is the diameter of the cylinder.

From Eq. 5, if $\Delta T=50 \mathrm{~K}$ and $\mathrm{d}=0.141 \mathrm{~m}$, then $h_{c}=5.72 \mathrm{Wm}^{-2} \mathrm{~K}^{-1}$. The experimental result of the simulated motor at $P_{c}=50 \mathrm{~W}$ and $\Delta T=51 \mathrm{~K}$ for a bare aluminum surface is

$h_{c}=6.75 \mathrm{Wm}^{-2} \mathrm{~K}^{-1}$. The reason for this large value in the simulated motor is that the simulated motor is a finite length $(267 \mathrm{~mm})$, and convection occurs at the two end covers. The observed natural convection coefficient of the simulated motor is of the same magnitude and agrees with the results of Holman [4].

Coanda effect cooling from the nozzle, similar to PAC tube cooling is found in Song [6]. From Fig. 11 of [5] at $0^{\circ}$ angle, the Nusselt number, $\mathrm{Nu}=h_{c} \mathrm{D} / \mathrm{k}$, is 81 , where $\mathrm{D}$ is nozzle width $(0.025 \mathrm{~m})$ and $\mathrm{k}$ is thermal conductivity of air $\left(0.026 \mathrm{Wm}^{-1} \mathrm{~K}^{-1}\right)$. The convection coefficient is calculated as approximately $84 \mathrm{Wm}^{-2} \mathrm{~K}^{-1}$. This is the same order of magnitude seen in PAC tube tests.

In this experimental study, four different types of measurements were conducted: temperature, electric power (voltage and current), and length (to calculate the area). The estimated standard uncertainties corresponding to these measurements are: $0.1{ }^{\circ} \mathrm{C}$ for temperature, $0.001 \mathrm{~V}$ for voltage, $0.002 \mathrm{~A}$ for current, and $0.050 \mathrm{~mm}$ for length.

\section{Conclusions}

It has been observed that the temperature differences between the surface of the simulated motor and the ambient air, $\Delta T$, dropped from $80.7 \mathrm{~K}$ by using natural convection to $2.8 \mathrm{~K}$ by using the NSF PAC tubing without the vortex device at $84 \mathrm{~W}$. It is determined that under simulated experimental conditions, cooling by the PAC tubing improves the temperature difference, T, by up to 28 times compared to cooling by natural convection.

It is also demonstrated that cooling as defined by temperature drop or convection coefficient by the NSF PAC tubing without vortex device is about 3 times more effective than cooling by the blower at high speed.

The effect of a black painted surface radiates as much heat loss as does natural convection. Therefore, to reduce the temperature from a heat source, it is better to paint the surface of heat sources with black paint whenever possible.

Although the vortex device reduced the temperature of inlet air by about $10 \mathrm{C}$, it also reduced the airflow rate in the PAC tubing to approximately one third. It is concluded that it is better to use PAC 
tubing without a vortex device. It has been found that the more airflow, the more cooling occurs. The tradeoff of greatly reduced airflow for a small inlet air temperature reduction is not effective.

The airflow pattern from PAC tubing was not studied. How much the PAC tubing generates the Coanda effect is yet to be studied.

In general, it can be concluded that PAC tubing is an inexpensive, simple, and easy-to-use method for cooling machine tool components if it can be applied near the heat sources. However, the effectiveness of the PAC tubing for temperature control of machine tool structures is yet to be tested. For example, in a machine tool spindle, heat is generated by the bearings and is dissipated through the inner and outer races. The heat generated and dissipated in the inner race influences most of the spindle thermal growth. The PAC tubing cannot be easily mounted to the rotational parts of the bearings. In addition, the heat generated by an actual spindle is much larger than $84 \mathrm{~W}$. Therefore, it is expected that the effectiveness of spindle cooling with the PAC tubing will not be as high as that observed in this study.

If the PAC tubing works to maintain a lower spindle and motor temperature, this system can be applied to many machine tools to reduce temperature gradients across the machine structure.

Acknowledgement: This project was carried out under CRADA (Cooperative R\&D Agreement) CN-1755 with TEXAN Corp. The authors thank the TEXAN Corp. for its support, and express special appreciation to Fred Pirkle, Nick Tallos, and Douglas Kimball of TEXAN Corp. for their willingness to modify the PAC tube design for this study.

Disclaimer: Certain commercial equipments or materials are identified in this report. Such identification does not imply recommendation or endorsement by the National Institute of Standards and Technology.

\section{REFERENCES}

[1] J. B. Bryan, D.L. Carter, R. W. Clouser, and J.H. Hamilton, "An Order of Magnitude Improvement in Thermal Stability with use of Liquid Shower in a General Purpose Measuring Machine," SME Precision Machining Workshop, June 1982.

[2] I. Reba, Applications of the Coanda Effect, Scientific American, Vol. 214, p. 84 (1966).

[3] W. M. Rohsenow and H. Y. Choi, Heat, Mass, and Momentum Transfer, Prentice-Hall, Englewood Cliffs, N. J. (1961).

[4] J. P. Holman, Heat Transfer, McGraw-Hill, New York (1986), p. 346.

[5] H. B. Song, S. H. Yoon, and D. H. Lee, "Flow and heat transfer characteristics of a twodimensional oblique wall attaching offset jet," Intl. J. Heat Mass Transfer 43, p. 2395-2404 (2000). 


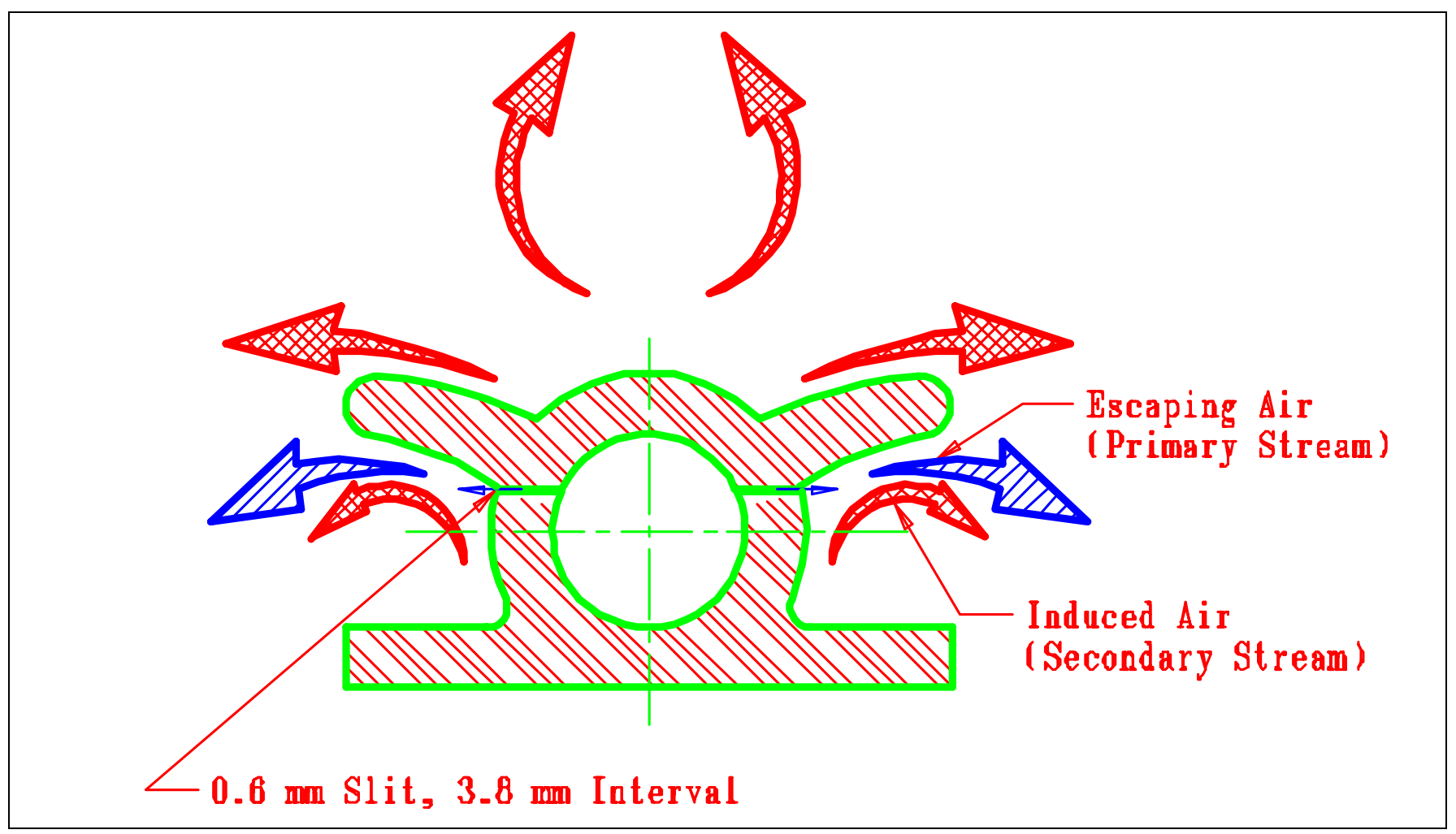

Fig. 1 Cross-Section of PAC tubing

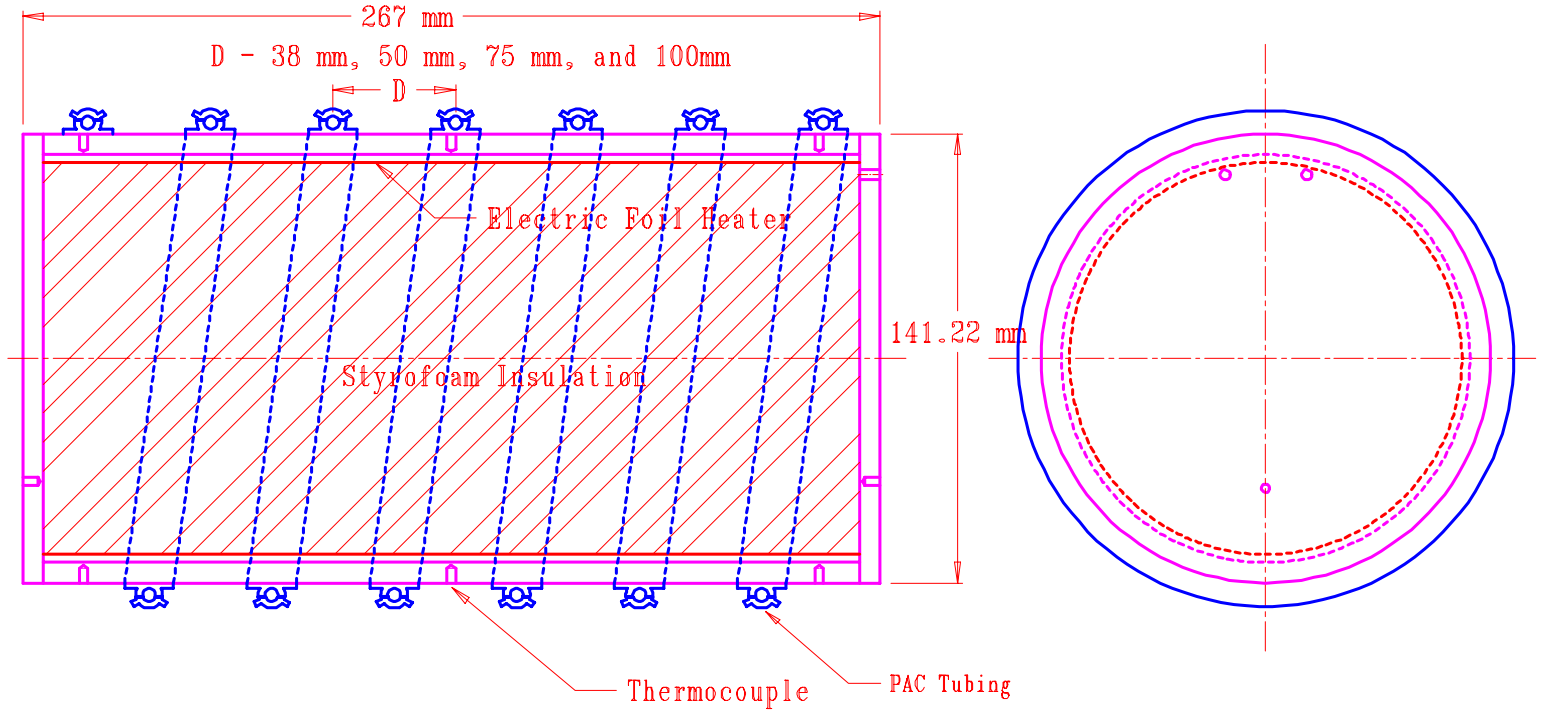

Fig. 2 Simulated Motor with PAC Tubing 


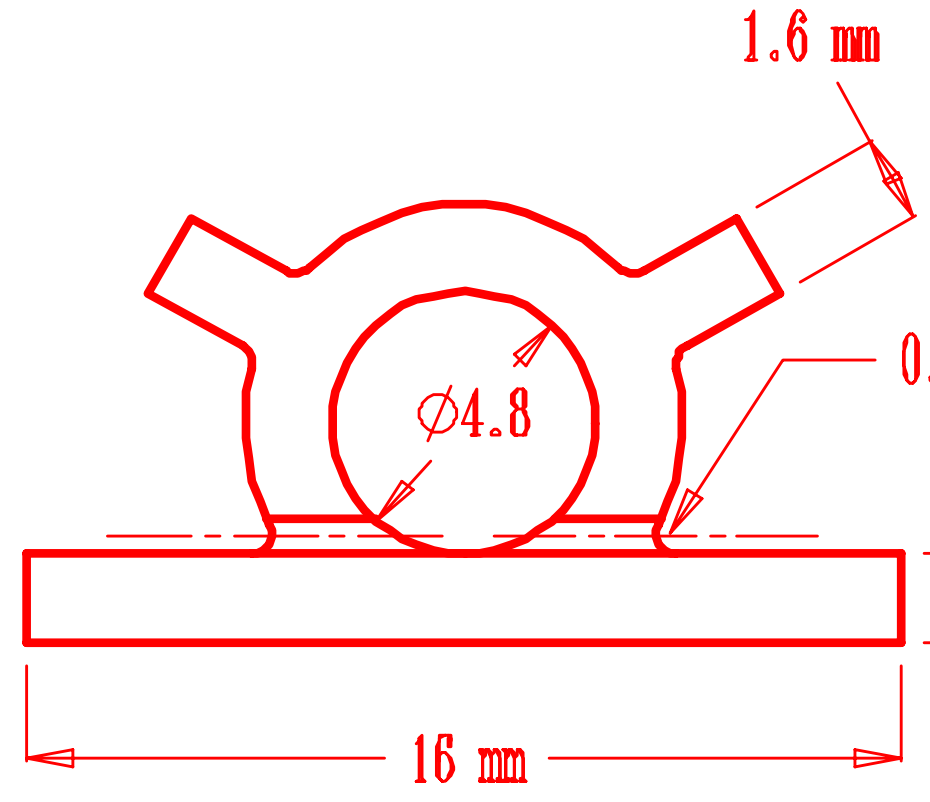

Modified SF Tubing Cross-Section - Model NSF

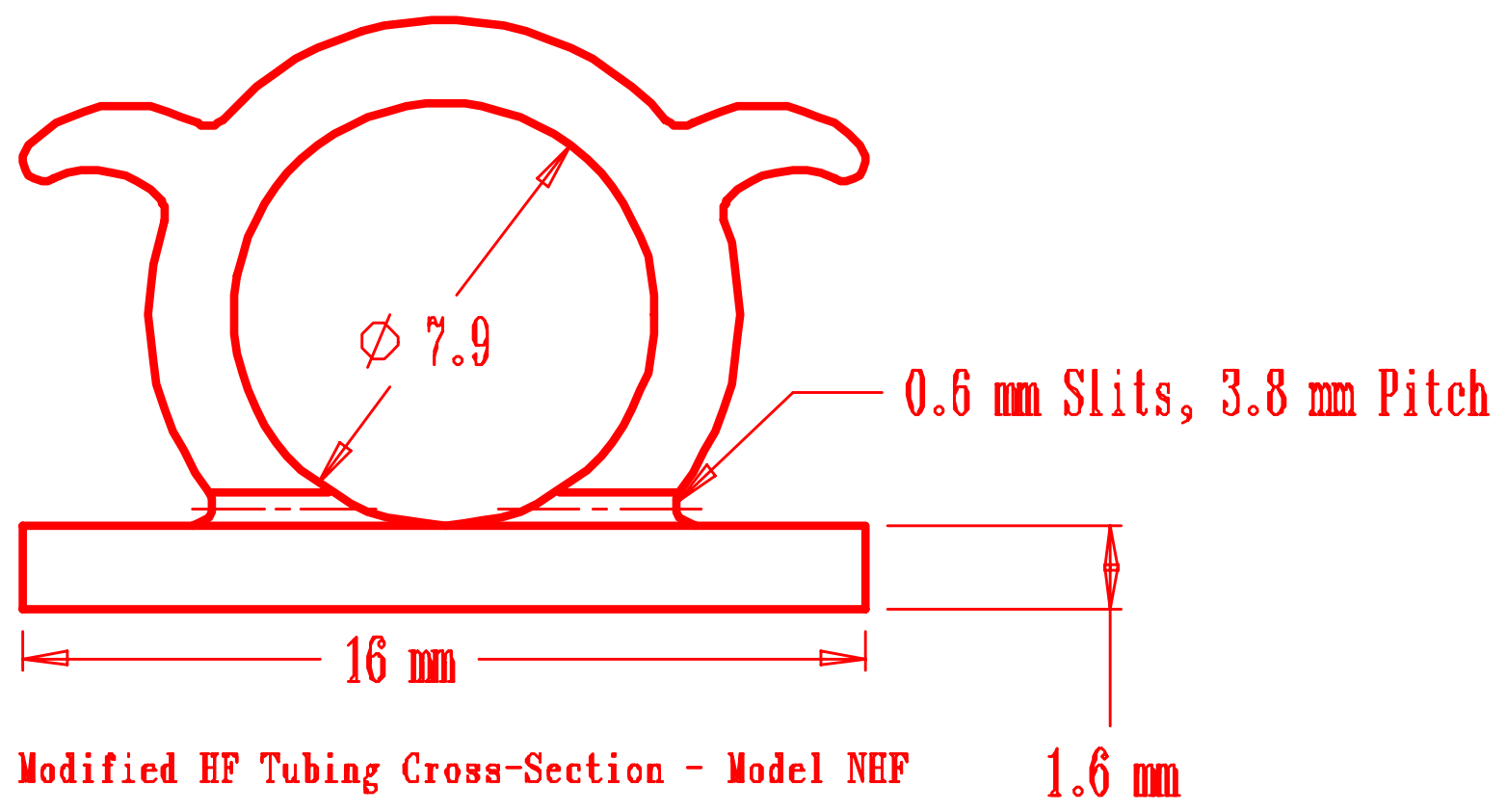

Fig. 3 Cross-Section of NSF and NHF PAC tubing 


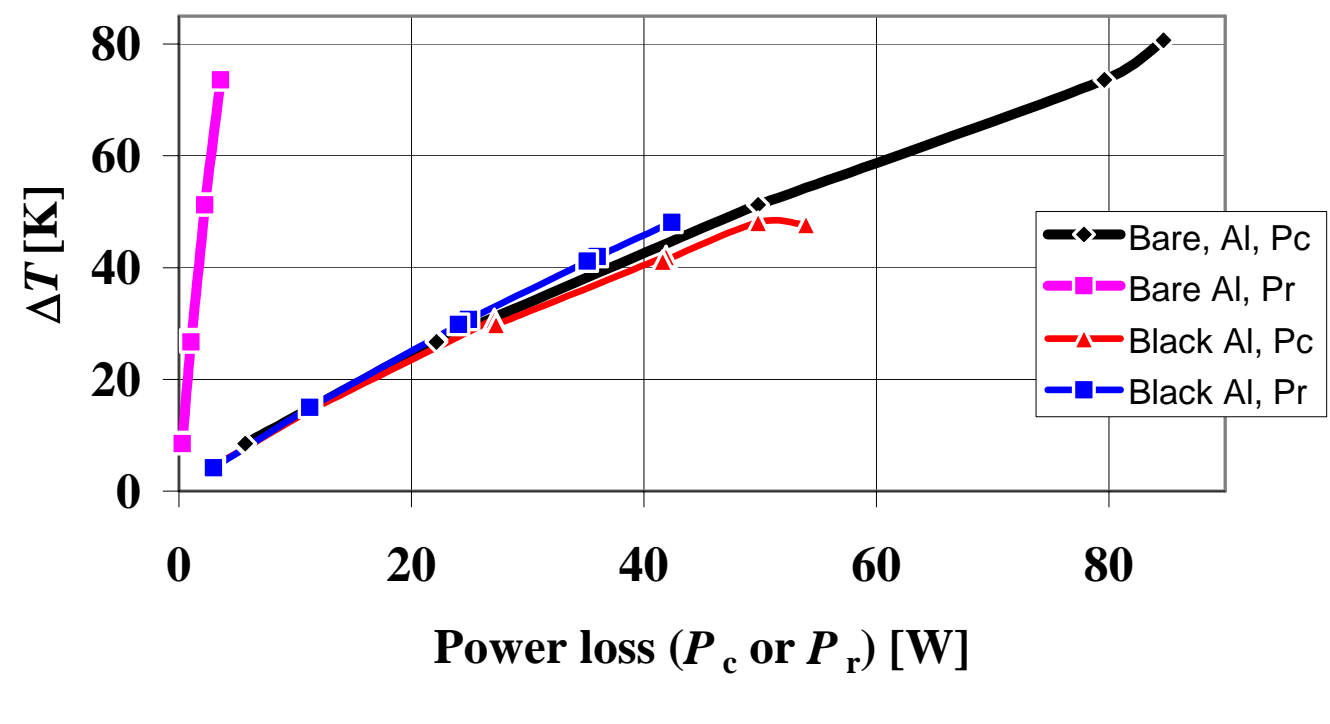

Fig. 4 Radiation and convection cooling of bare and black painted simulated motor (cooling is indicated by the difference between the surface temperature and the ambient temperature)

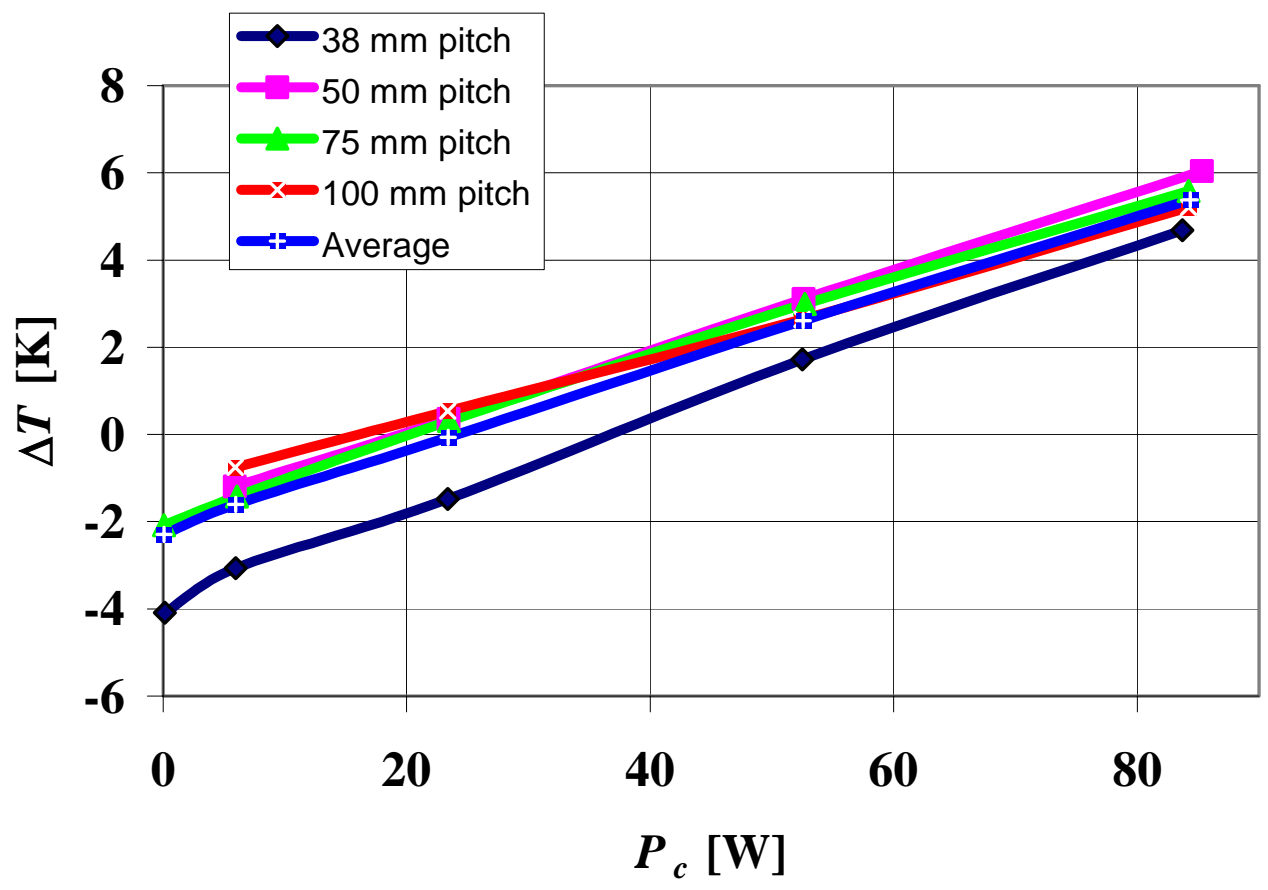

Fig. 5 Cooling test results using SF PAC tubing with vortex device 


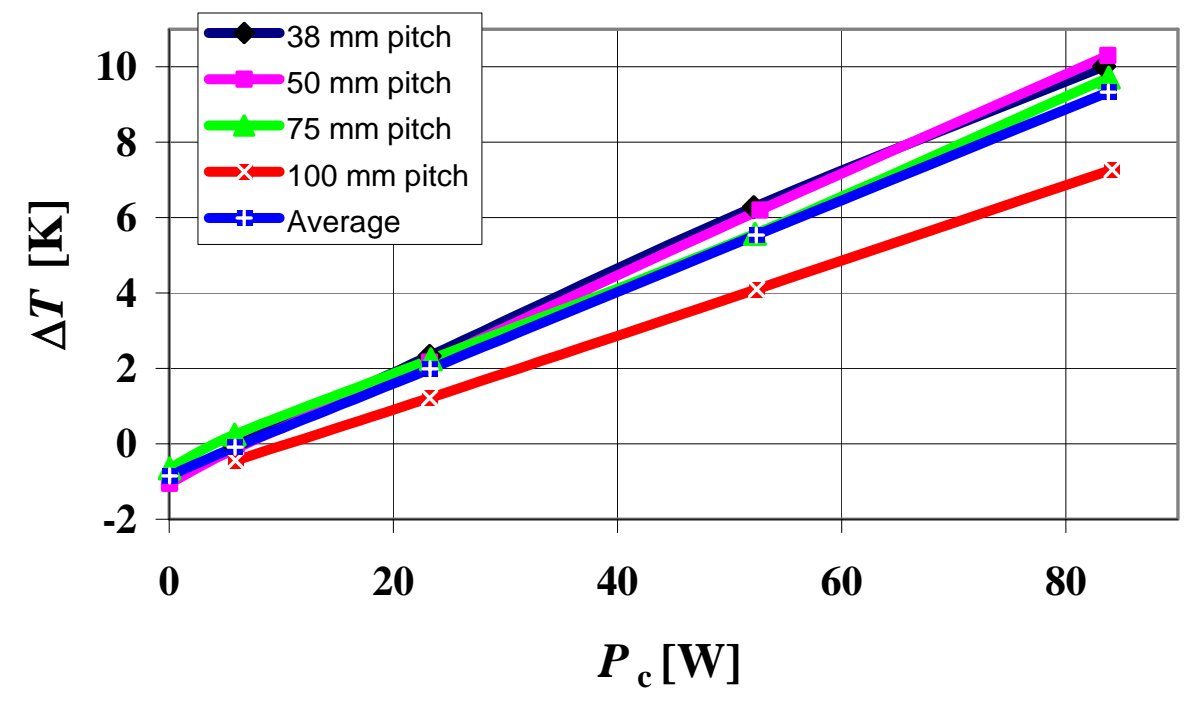

Fig. 6 Cooling test results using HF PAC tubing with vortex device

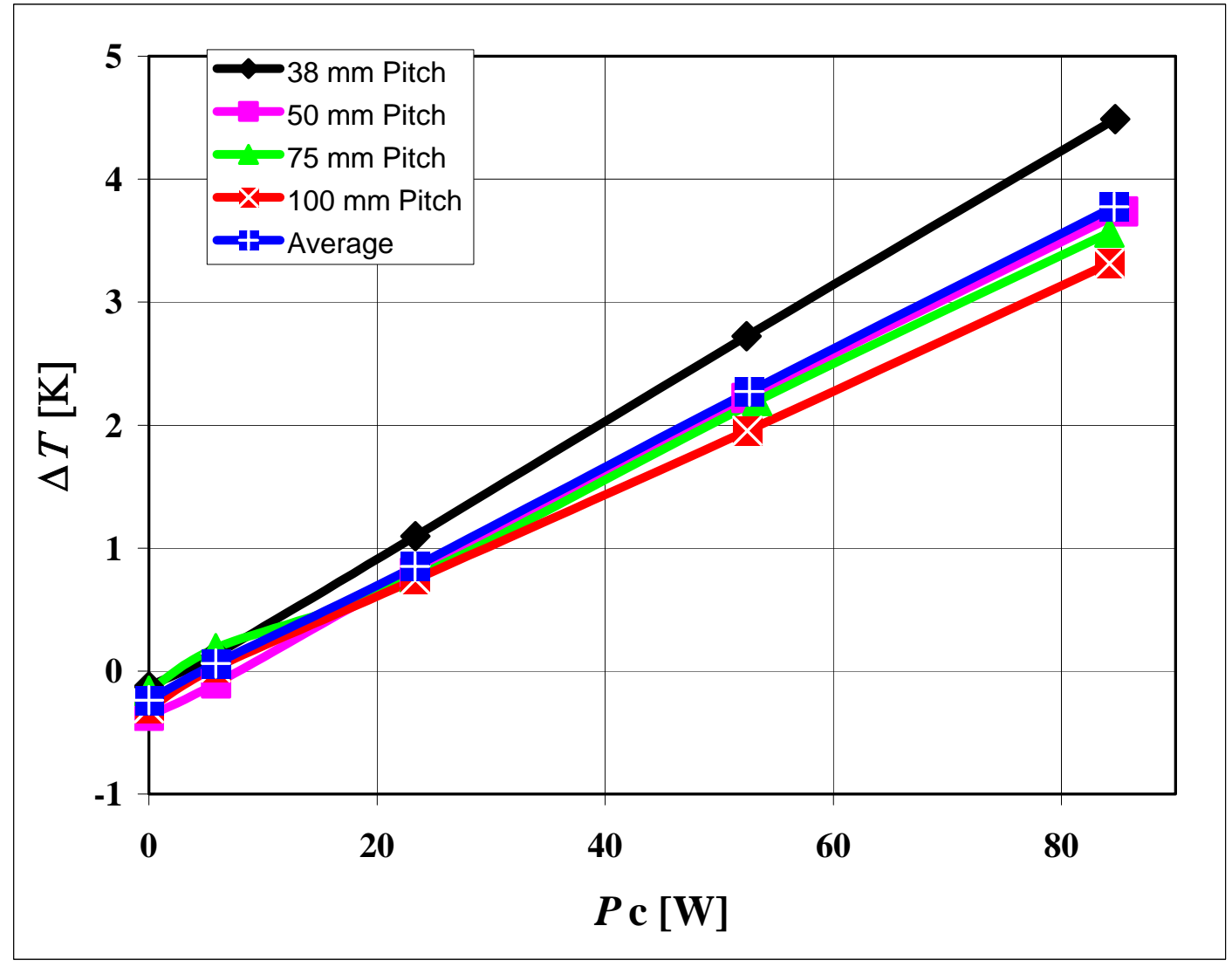

Fig. 7 Cooling test results using SF PAC tubing without vortex device 


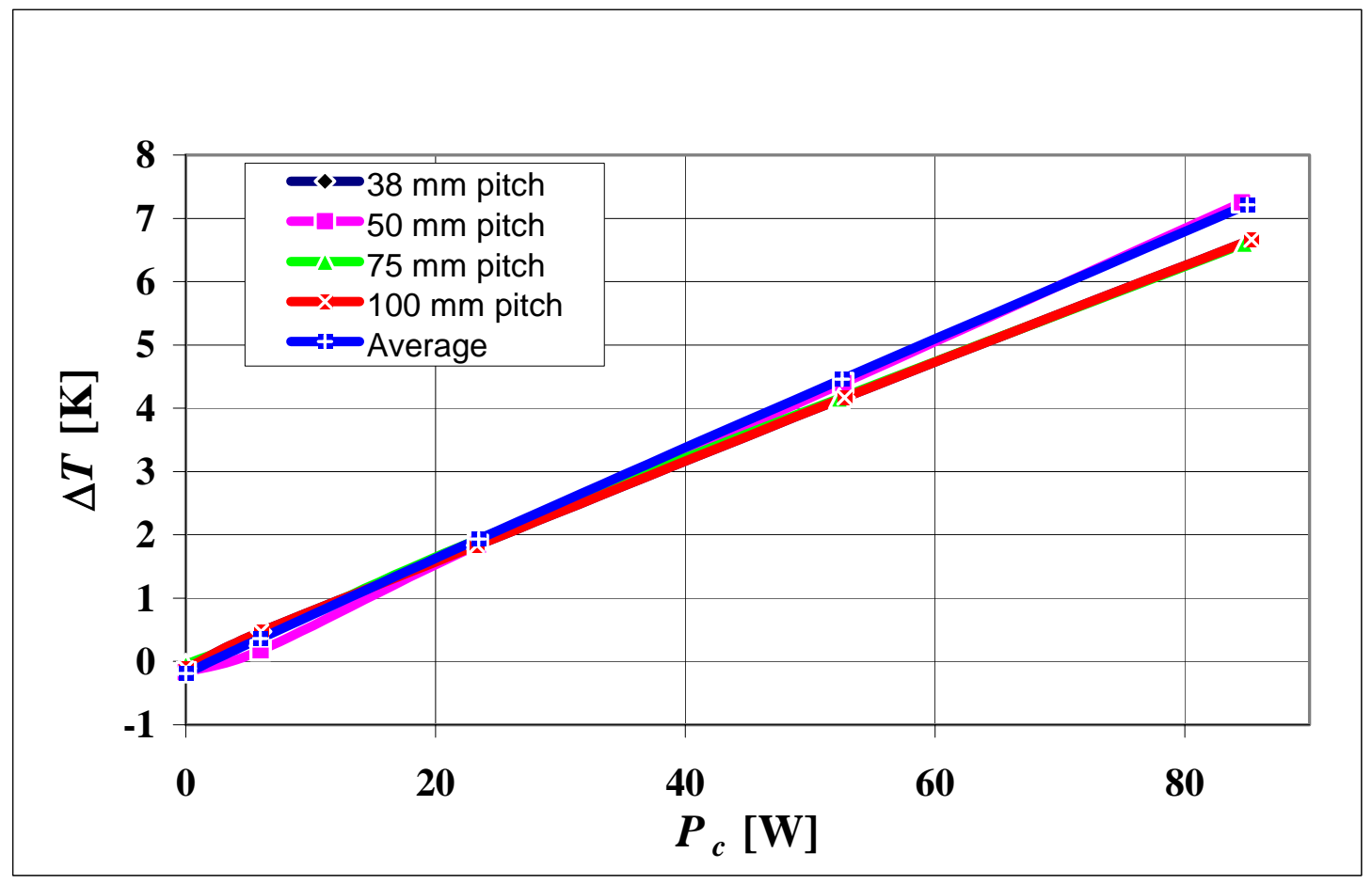

Fig. 8 Cooling test results using HF PAC tubing without vortex device

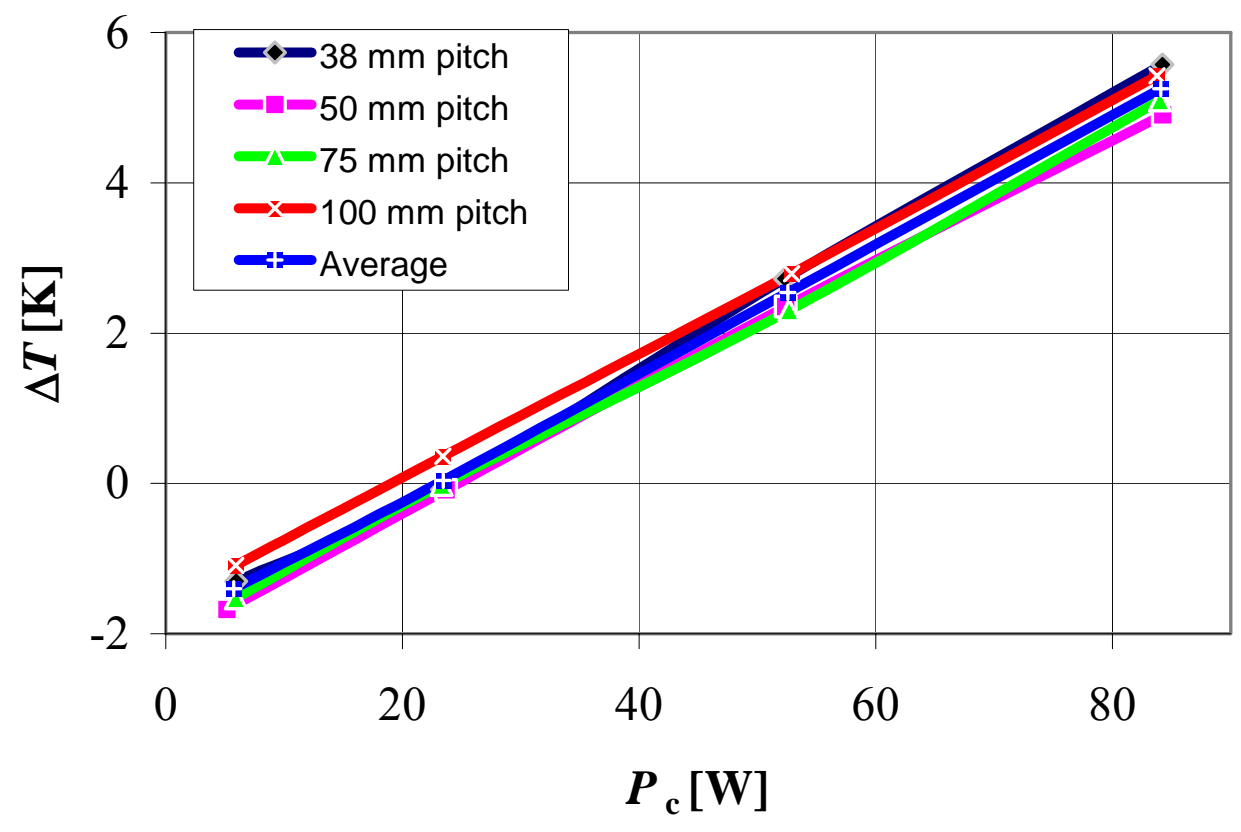

Fig. 9 Cooling test results using NSF PAC tubing with vortex device 


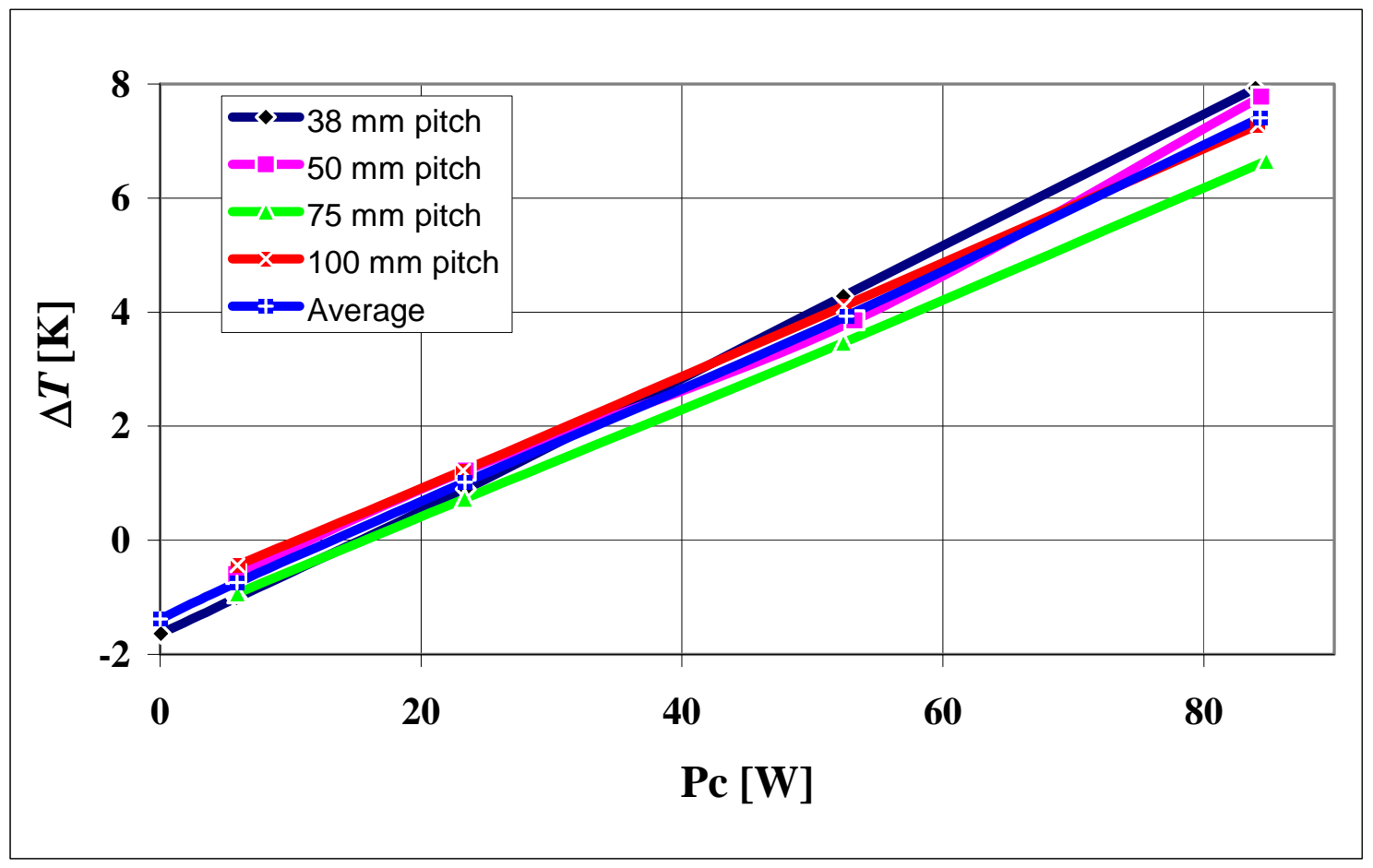

Fig. 10 Cooling test results using NHF PAC tubing with vortex device

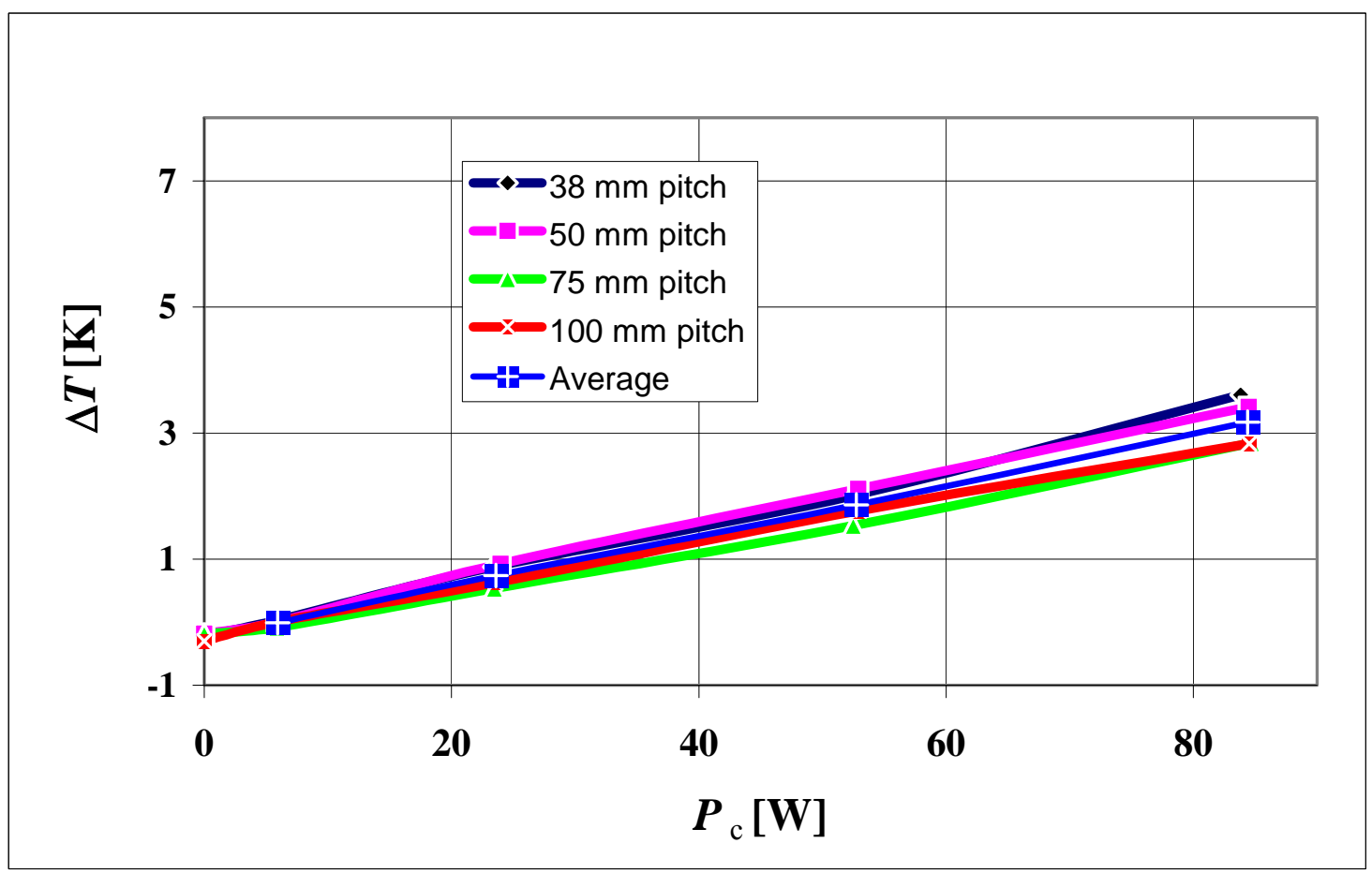

Fig. 11 Cooling test results using NSF PAC tubing without vortex device 


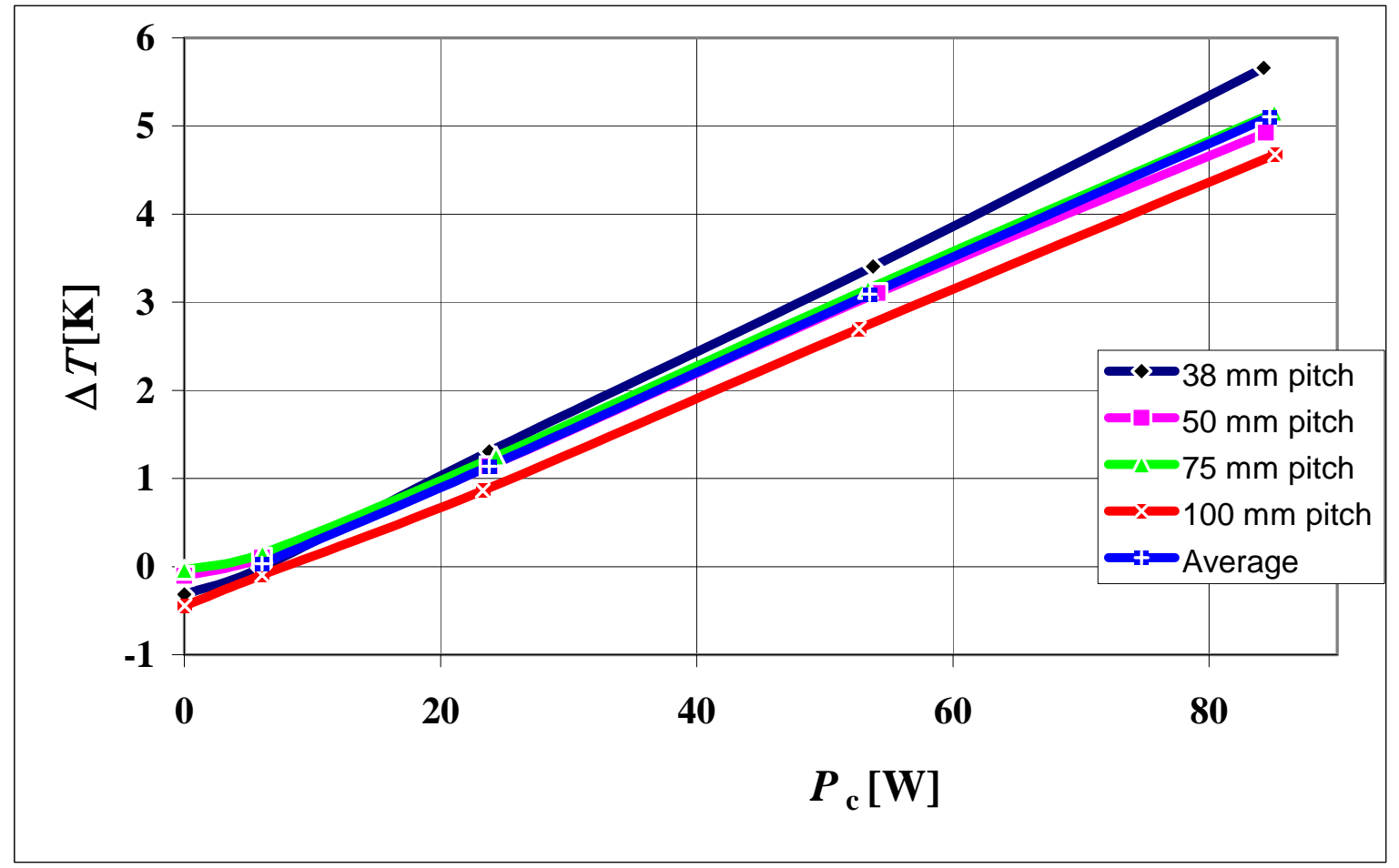

Fig. 12. Cooling test results using NHF PAC tubing without vortex device

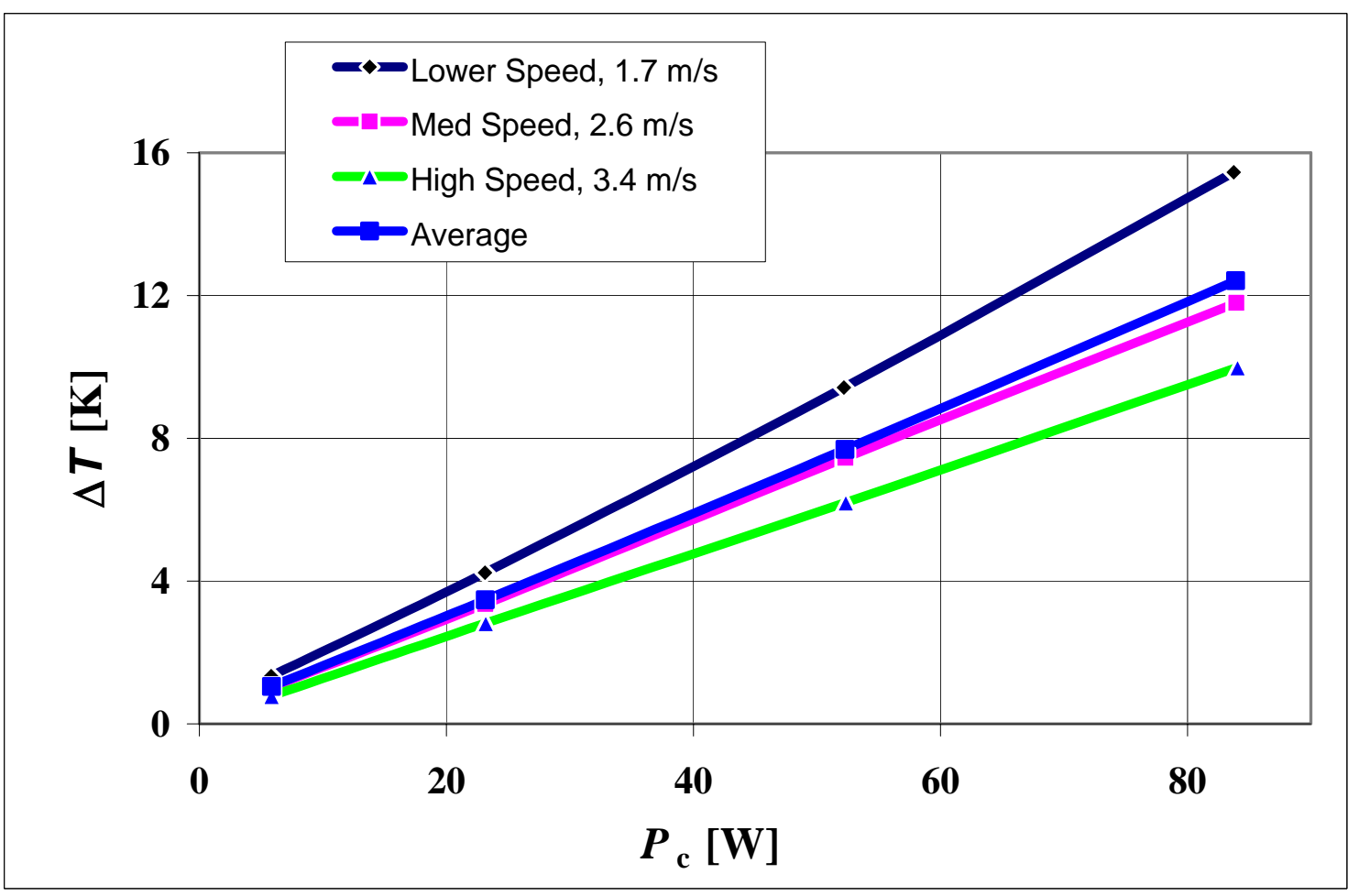

Fig. 13. Cooling test results using blower 


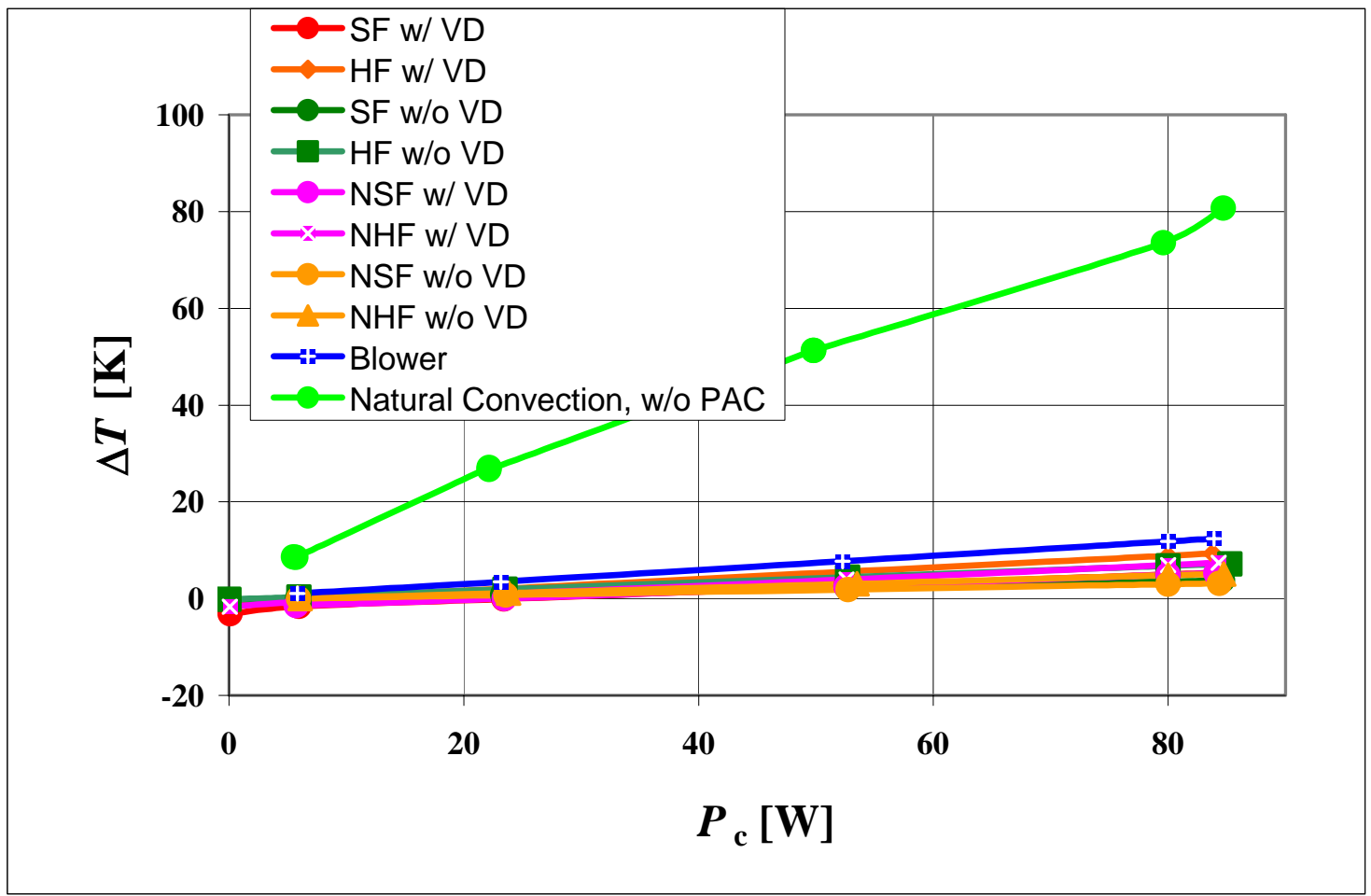

Fig. 14. Average cooling test results using PAC tubing

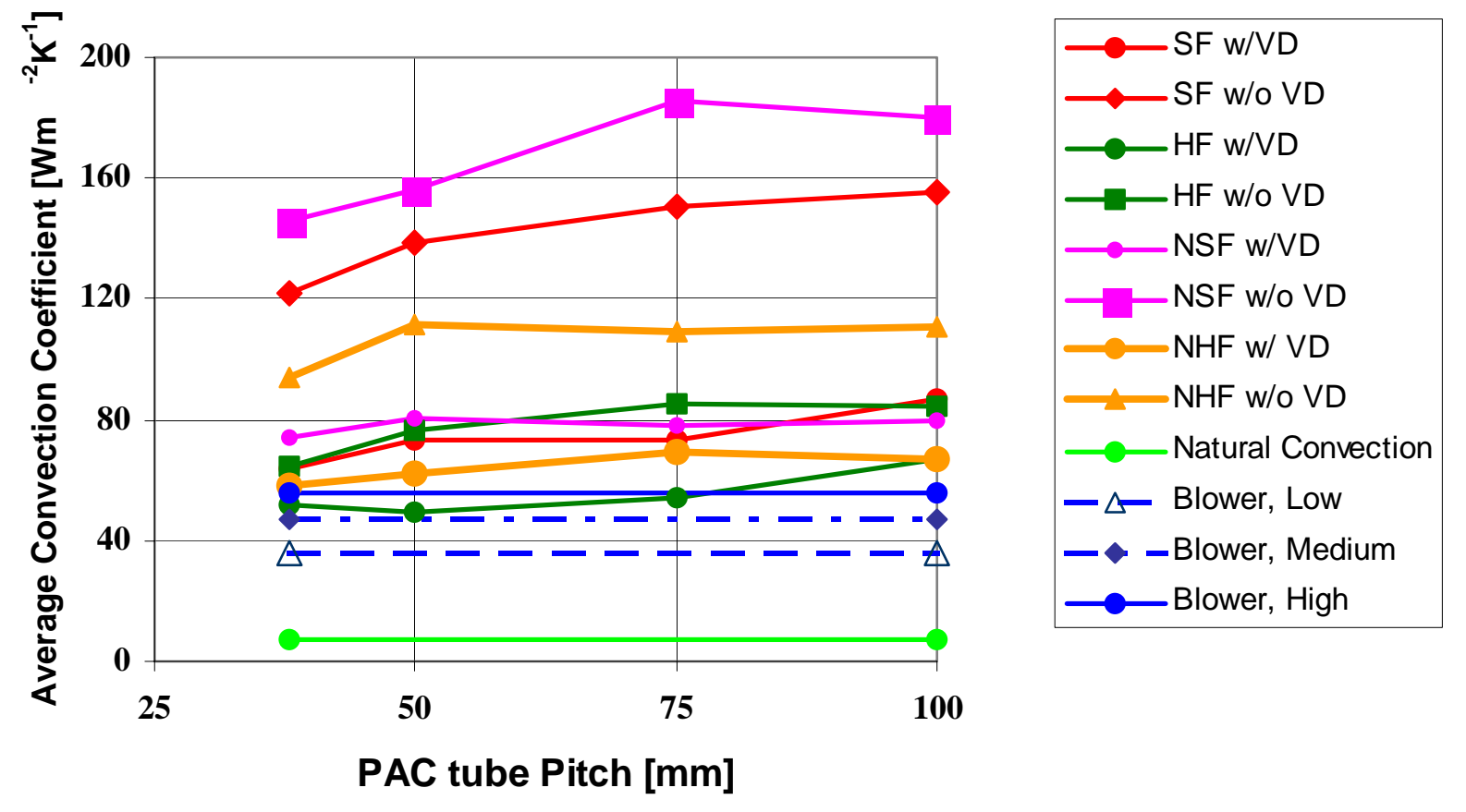

Fig. 15. Average convection coefficient 


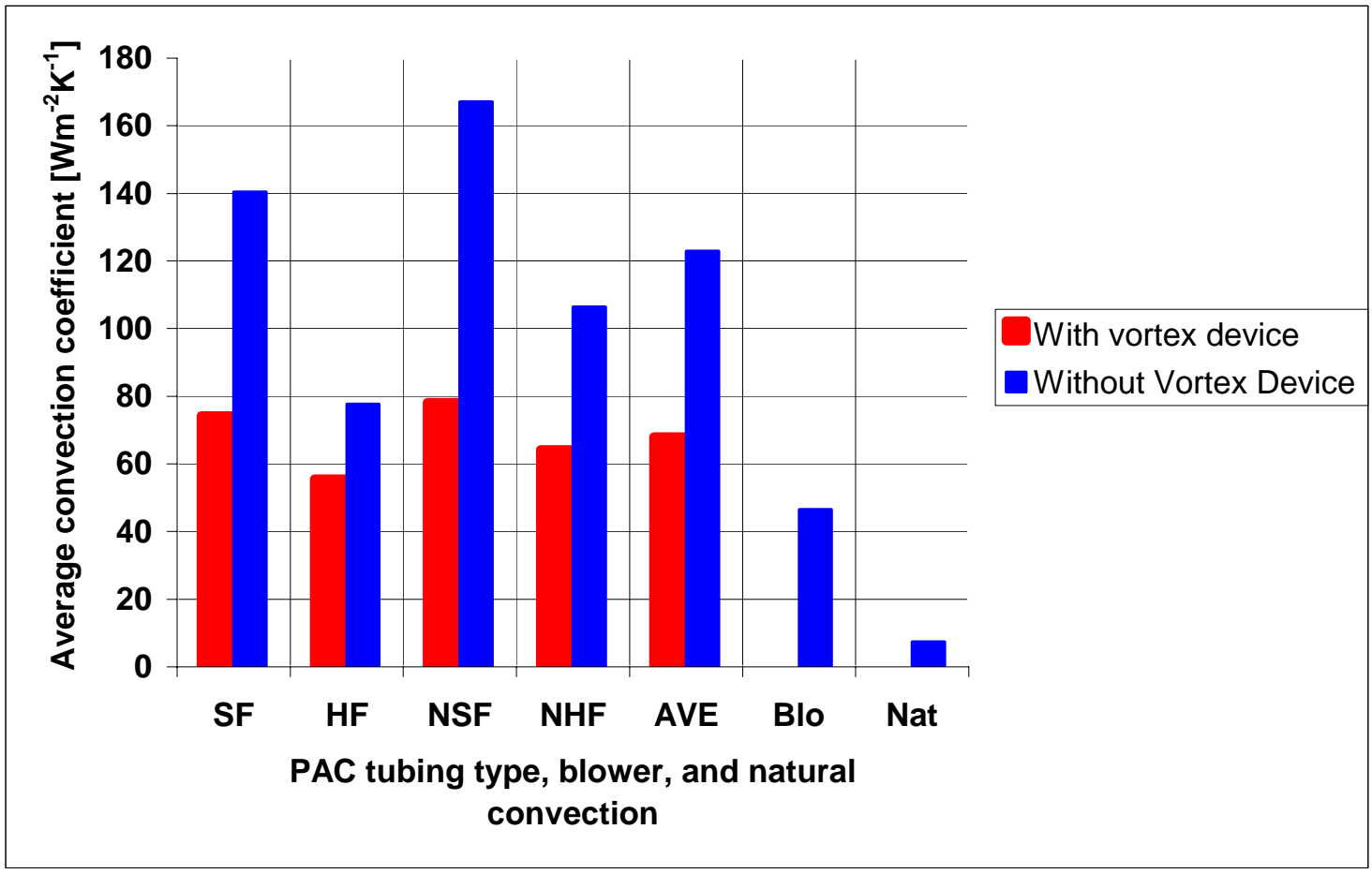

Fig. 16. Average convection coefficient of PAC tubing type, blower, and natural convection 